Article

\title{
Production of Bulk Metallic Glasses by Severe Plastic Deformation
}

\section{Lisa Krämer $^{1, *}$, Karoline S. Kormout ${ }^{1}$, Daria Setman ${ }^{2}$, Yannick Champion ${ }^{3}$ and Reinhard Pippan ${ }^{1,4}$}

${ }^{1}$ Erich Schmid Institute of Materials Science, Austrian Academy of Sciences, Leoben 8700, Austria; E-Mails: karoline.kormout@oeaw.ac.at (K.S.K.); reinhard.pippan@ oeaw.ac.at (R.P.)

${ }^{2}$ Physics of Nanostructured Materials, Faculty of Physics, University of Vienna, Vienna 1090, Austria; E-Mail: daria.setman@univie.ac.at

${ }^{3}$ Institut de Chimie et des Matériaux Paris-Est, Université Paris-Est Créteil, Thiais 94320, France; E-Mail: champion@icmpe.cnrs.fr

${ }^{4}$ Department of Materials Physics, University of Leoben, Leoben 8700, Austria

* Author to whom correspondence should be addressed; E-Mail: lisa.kraemer@stud.unileoben.ac.at; Tel.: +43-3842-804-228

Academic Editor: Heinz Werner Hoppel

Received: 31 March 2015 / Accepted: 23 April 2015 / Published: 30 April 2015

\begin{abstract}
The aim of this study was to show the possibility to produce bulk metallic glass with severe plastic deformation. High pressure torsion was used to consolidate Zr-based metallic glass powder and deform it further to weld the powder particles together. The produced samples were investigated with Scanning electron microscope (SEM), Transmission electron microscope (TEM), Differential scanning calorimetry (DSC) and X-ray diffraction (XRD) to check if the specimens are fully dense and have an amorphous structure. The results show that the specimens remain amorphous during high pressure torsion and the density depends on the applied strain. Additional Vickers hardness measurements enable a comparison with literature and show for Zr-based metallic glass powder typical values (approximately $500 \mathrm{HV}$ ).
\end{abstract}

Keywords: severe plastic deformation; bulk metallic glass; $\mathrm{Zr}$ 


\section{Introduction}

Metallic glasses are a new class of metals which were discovered in the 1950s [1-4]. As a consequence of their amorphous structure, they have no crystal defects as grain boundaries or dislocations $[2,5,6]$. This microstructural state changes the mechanism of deformation and subsequently their mechanical properties. Their high yield strength and high elastic strain qualifies them for various applications $[7,8]$. But as any new developed material they also harbor some obstacles. Metallic glasses are not easy to produce as crystallization of the melt must be prevented. This can be difficult depending on the used composition and the aimed large dimensions $[9,10]$. A solution for producing bulk metallic glasses from not so stable metallic glass compositions is to produce metallic glass powder and form the bulk metallic glass in an additional step. Severe plastic deformation (SPD) can be this additional step $[11,12]$ as well as a powder metallurgy process [13-15]. SPD techniques were used in the past to obtain ultra-fine grained (ufg) and nanocrystalline (nc) specimens [16-19]. A wide range of materials was processed with SPD and even immiscible systems were deformed to obtain nanocomposites [20]. The flexibility of these routes is also shown in the used starting materials. Those can range from solid to powder and so the process of alloying is simplified. If High Pressure Torsion (HPT) is used, powders can simply be mixed and the achieved mixture consolidated. With the applied strain during the following HPT step the material becomes homogenous. SPD was already used to deform bulk metallic glass samples and even metal-metallic glass composites were obtained [21-25].

The aim of this study was to produce bulk metallic glass samples with SPD. The Zr-based metallic glass powder was consolidated and deformed with HPT. SEM, TEM, XRD, DSC and hardness measurements were used to investigate the specimen.

\section{Experimental Section}

For the production of bulk metallic glass samples a metallic glass powder with the composition $\mathrm{Zr}_{57} \mathrm{Cu}_{20} \mathrm{Al}_{10} \mathrm{Ni}_{8} \mathrm{Ti}_{5}$ has been used. This powder was prepared by high pressure gas atomization (atomization performed by Lucas Dembinski, PERSEE, IRTES-LERMPS, Belfort France) and shows an average particle size of $25 \mu \mathrm{m}$ [21]. SEM images of the bulk metallic glass powder can be seen in Figure 1. A contamination particle is indicated with an arrow (see Figure 1b). Energy dispersive X-ray spectroscopy (EDX) measurements (Oxford Instruments plc, Abdingdon, UK) have shown that contamination contains $\mathrm{Mn}, \mathrm{Si}, \mathrm{Fe}, \mathrm{Al}$ and $\mathrm{Mg}$. For the HPT process (Schenck, Germany; adapted hydraulic testing machine), powder was filled between the gap of the grooved HPT anvils, where it was then compacted and processed by torsion under a pressure of $8 \mathrm{GPa}$ at room temperature up to 63 revolutions. The final dimensions of the samples used in this study are $6 \mathrm{~mm}$ in diameter and $0.6 \mathrm{~mm}$ in height. Some contaminating particles were too hard to be deformed simultaneously with the metallic glass powder. They, however, do not seem to influence the results of the general microstructure (their total amount is below 1\%); they may affect the ductility which is not in the focus of this paper. The deformed HPT disks were cut into halves, ground and polished for SEM investigations and hardness measurements. The Vickers hardness was measured along the diameter in the cross-section of the HPT sample with a load of $0.5 \mathrm{~kg}$. XRD phase analysis of the samples was performed using a 5-circle X-ray diffractometer (SmartLab, Rigaku Co., Tokyo, Japan) equipped with a source for $\mathrm{Cu}-\mathrm{K} \alpha$ radiation. 
DSC was performed using a Netzsch DSC 204 (NETZSCH GmbH \& Co.Holding KG, Selb/Bavaria, Germany). The heating range was between 25 and $590{ }^{\circ} \mathrm{C}$. The heating rate was $10 \mathrm{~K} \mathrm{~min}^{-1}$. For the DSC measurements undeformed powder and HPT samples, which were cut in half, were used. TEM samples were prepared by a standard procedure: grinding, polishing and dimple grinding with subsequent ion milling. TEM micrographs were recorded in top view at a radius of $2 \mathrm{~mm}( \pm 0.3 \mathrm{~mm}$ due to varying dimension and position of the hole). Microstructural investigations were conducted using a SEM LEO1525 (Carl Zeiss AG, Oberkochen, Germany) and a (scanning) transmission electron microscope (S)TEM JEOL JEM 2100F (JEOL Ltd., Akishima, Japan) equipped with a $\mathrm{C}_{\mathrm{S}}$-corrector (CEOS GmbH, Heidelberg, Germany).


Figure 1. SEM images of the Zr-based metallic glass powder. The average particle size is $25 \mu \mathrm{m}$. The spherical shape (a) is a result of the production by high pressure gas atomization. Contaminating particle indicated with an arrow in (b).

\section{Results and Discussion}

This work studies the possibility to produce bulk metallic glass specimens by using HPT; starting with compaction of metallic glass powder and subsequent deformation. Therefore, three essential questions must be answered: Is the final sample fully dense or does the sample contain pores or cracks? Does the structure of the metallic glass change during deformation? Is the hardness of the HPT produced metallic glass comparable to values of bulk metallic glass in literature?

To answer the first question samples were investigated in the SEM to find (even very small) inhomogeneities. In HPT the torsion of the sample leads to a strain gradient along the radius of the sample. At the center the applied shear strain is nearly zero, but at the edge it increases linearly with the radius. Hence, only few HPT disks are sufficient to investigate the influence of the applied strain. The investigated sample was deformed for 30 rotations at room temperature and cut into halves. Figure 2 and Figure 3 show the center and the edge in the cross-section of the HPT disk with a shear strain of approximately 0 and 900 , respectively.

In Figure 2, crack-like defects can be seen. These cracks are not induced by deformation, they are a consequence of the insufficient deformation of the initial powder particles. The distance between these 
defects corresponds to the particle diameter; it is between 2 and $25 \mu \mathrm{m}$ (see Figure 1). Those cracks can be found up to a radius of approximately $1.5 \mathrm{~mm}$, which equals to a shear strain of about 600 . Apparently, the deformation near the center was not large enough to enforce a full consolidation of the powder and fully weld the particles together.
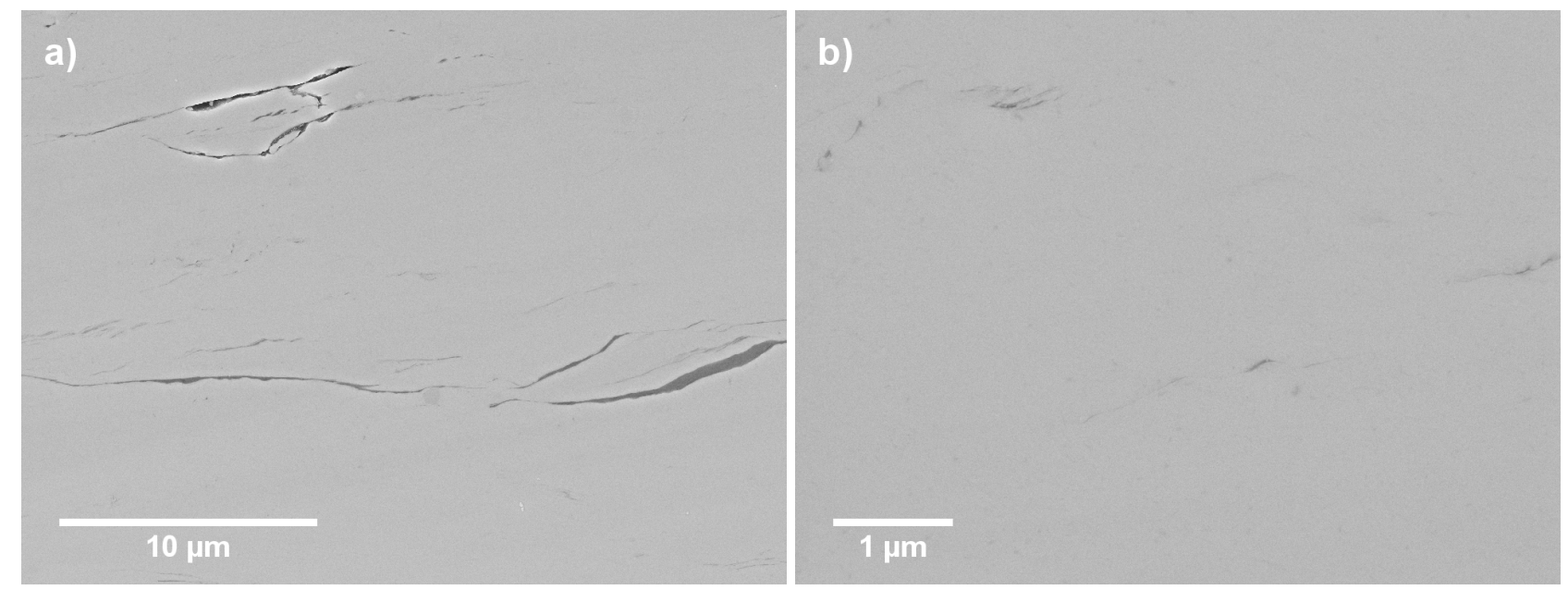

Figure 2. SEM images taken from regions near the center of the High Pressure Torsion (HPT) disk at different magnifications (lower magnification (a) and higher magnification (b)). The crack-like defects are the result of unfinished welding of the metallic glass powder. The distance between the cracks correlates with the particle size of the powder.
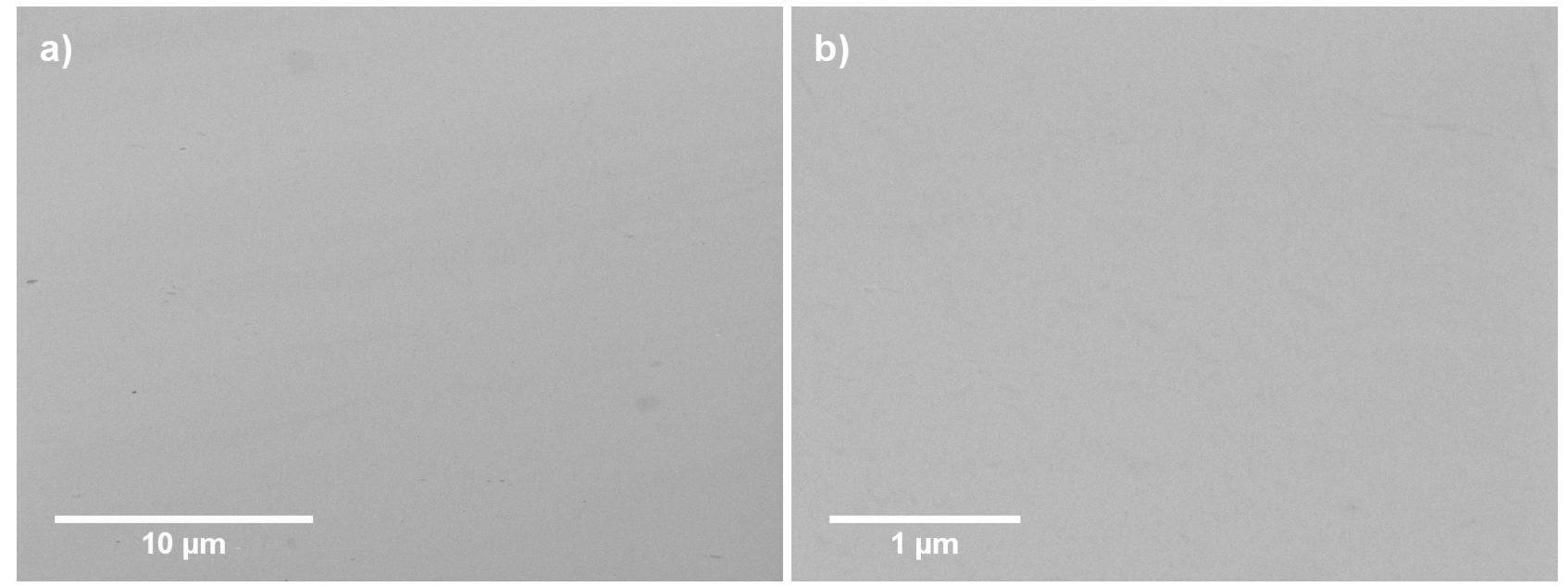

Figure 3. SEM images near the edge of the HPT disk. At low magnifications (a) and even at high magnifications (b), no cracks, pores or other inhomogeneities can be detected.

At the edge of the same specimen (Figure 3), no cracks or pores can be detected. So, these SEM images confirm that full density is reached after sufficient deformation of the specimen. No other features are visible in the SEM images due to the absence of cracks, pores and boundaries.

$\mathrm{XRD}$ and DSC measurements as well as TEM imaging were used to investigate the microstructure of the HPT deformed specimen. In XRD broad peaks are expected for an amorphous material, while 
crystalline materials would show several sharp peaks depending on the crystal structure and the lattice parameters. The position of the metallic glass peak depends on the present short-range order, which is strongly influenced by the composition. In Figure 4, the XRD results of the undeformed powder and a deformed specimen are presented. A broad peak typical for amorphous material can be seen for the HPT deformed sample (black line) and the undeformed powder (gray line). The position and width of the peaks are identical and this confirms that bulk metallic glass can be produced by HPT using metallic glass powder. For the used Zr-based metallic glass the broad peaks are in the same angle range as the peaks of crystalline $\mathrm{Zr}$. Shifting of this angles is due to the other elements, such as $\mathrm{Cu}$ and $\mathrm{Ni}$.

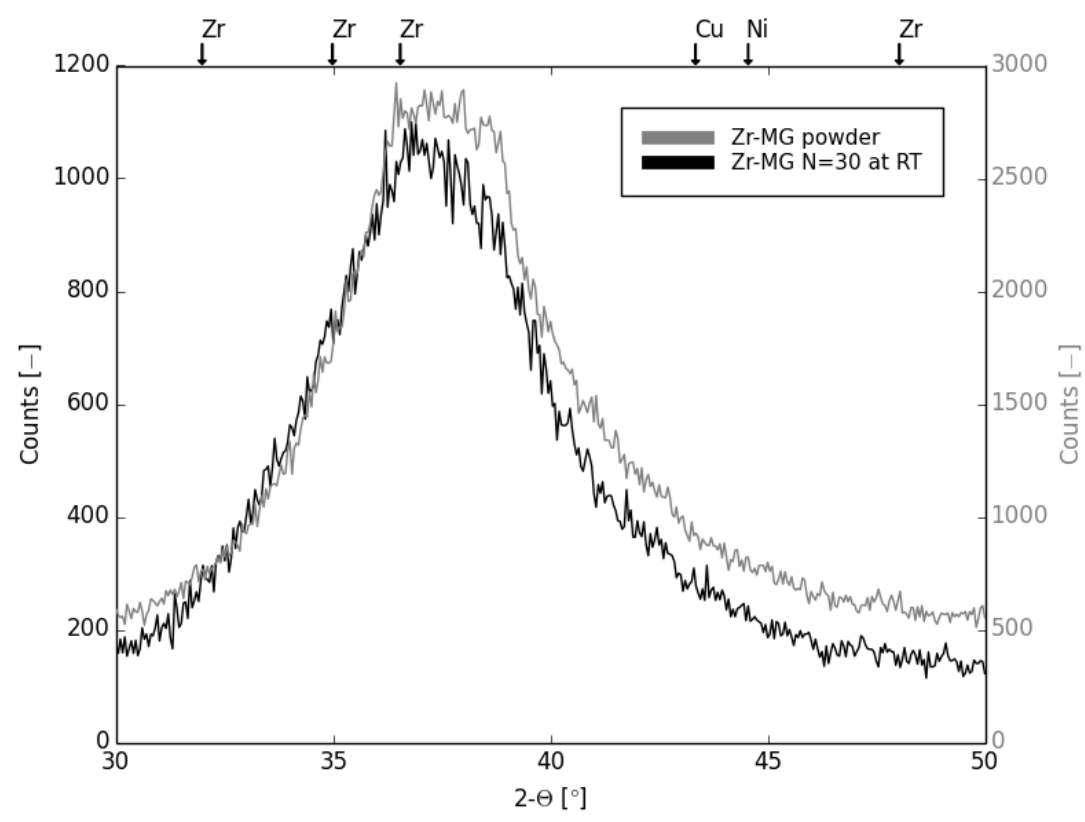

Figure 4. XRD measurement of the HPT deformed sample and the undeformed powder (gray line). The peak position and width are in both cases the same, which indicates an unchanged amorphous structure after HPT deformation. The arrows indicate the peak positions of crystalline $\mathrm{Zr}$, $\mathrm{Ni}$ and $\mathrm{Cu}$. The number of counts differs as different slits were used during the XRD measurements.

Additionally, the specimen was examined in TEM to confirm that the material is still amorphous after HPT deformation. In Figure 5, a high resolution TEM image and the diffraction pattern for the same position are shown. In the TEM image no ordered region is visible. The diffraction pattern consists of two broad rings only, which indicates-analog to the XRD measurements-an amorphous state of the sample.

DSC measurements substantiate the results of XRD and TEM. Two HPT disks with 10 and 30 turns at room temperature and undeformed powder were measured and the results can be seen in Figure 6. All three specimens crystallize at nearly the same temperature $\left(460^{\circ} \mathrm{C}, 457^{\circ} \mathrm{C}\right.$ and $\left.455^{\circ} \mathrm{C}\right)$ and the crystallization peaks have got a very similar breadth. Therefore, it can be concluded that during HPT deforming no crystallization occurs. The onset of crystallization differs for the deformed specimen and the undeformed powder. This is caused by structural relaxation during the deformation as the high compressive loading of the HPT favors a structural change to a state with higher density (which equals 
a more relaxed state) [26]. The relaxation in the HPT specimen causes also a shift of the glass transition temperature to higher temperatures and a stronger overlap with the crystallization peak.

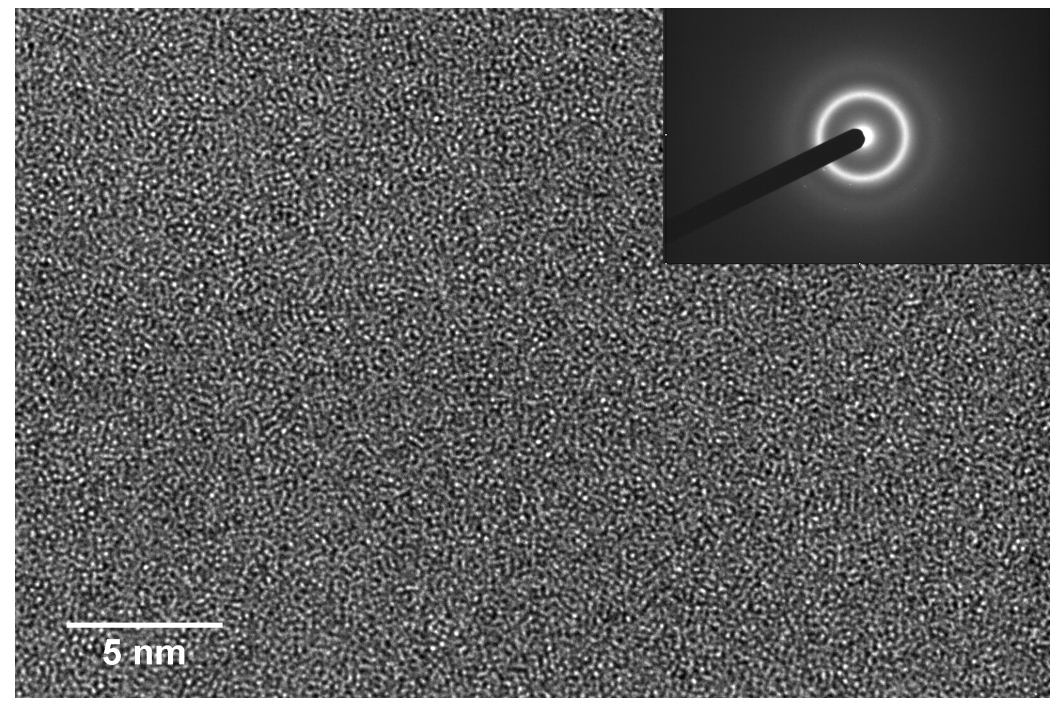

Figure 5. In the high resolution TEM image no ordered regions can be detected. The inset shows a diffraction pattern at the same position but from a much larger region (selected area diffraction (SAD) aperture size: $120 \mu \mathrm{m}$ ). The broad rings confirm the amorphous state of the specimen.

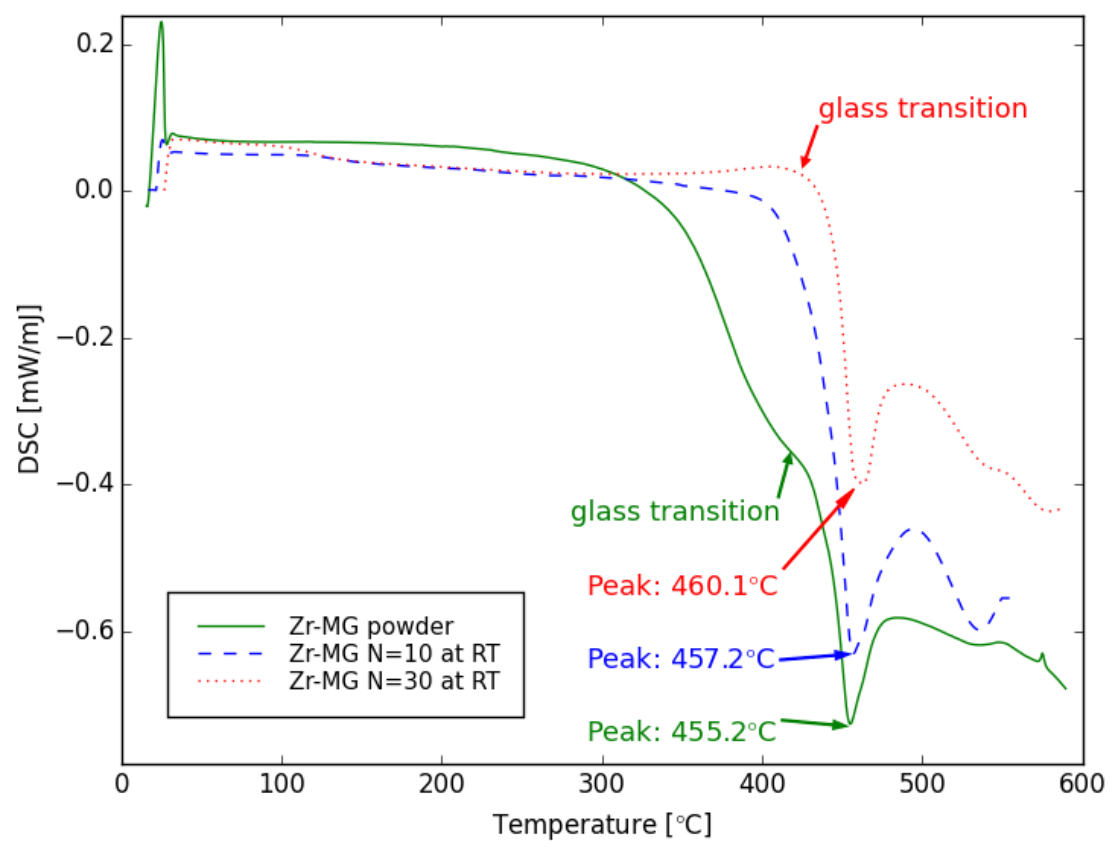

Figure 6. Differential scanning calorimetry (DSC) measurements exclude a crystallization during HPT deformation. The powder as well as the HPT disks show a distinctive crystallization peak at $457^{\circ} \mathrm{C}, 455^{\circ} \mathrm{C}$ and $460{ }^{\circ} \mathrm{C}$, respectively. The peak breadth and position are nearly the same, which indicates an amorphous structure for all. The difference in the onset of crystallization and in the transition temperature is caused by structural relaxation due to the HPT process. 
The Vickers hardness was measured to get information about the mechanical properties of the processed bulk metallic glass. In Figure 7, the results are shown for three specimens, which were deformed at room temperature for three different numbers of rotations (10, 30 and 63 turns). After ten turns the specimen contains crack-like defects all over the diameter as the applied strain was not high enough to fully consolidate the powder. This leads to a decrease of hardness. Only near the edge, the hardness nearly approaches the value of the other samples. The hardness of the specimens with 30 and 63 turns is similar. Near the center a minimum hardness with about $450 \mathrm{HV}$ is measured and at the edge it increases up to $500 \mathrm{HV}$. From the fact that the specimens with 30 and 63 rotation show nearly the same hardness it can be concluded that the hardness will not increase further more, even when additional deformation is applied. Hence, it is obvious that a saturation state is reached at the edge of the samples. The values of hardness for Zr-based glass in literature are in the range of $420--470 \mathrm{HV}$ (Stolpe et al. [24]), 455--475 HV (Luo et al. [27]), 480 HV (Champion and Perrière [28]) and 500 HV (Chen [29] and $\mathrm{Xu}$ et al. [30]). The variation in hardness seems to be caused by different compositions and production routes. Furthermore, one should take into account that HPT generated bulk metallic glass is heavily deformed.
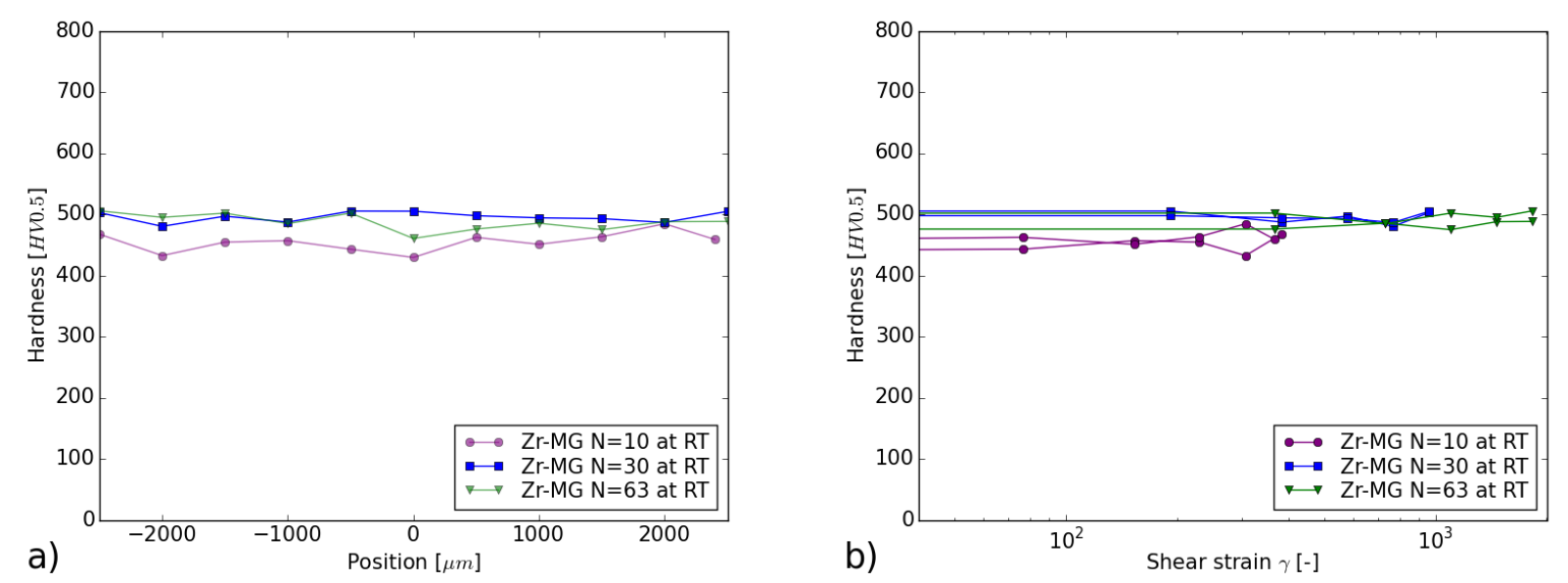

Figure 7. The results of Vickers hardness measurements can be seen. The hardness depending on the radius (a) of the HPT disk is shown as well as the hardness depending on the shear strain (b). Specimens with a higher number of applied rotations, show higher shear strain. For the sample with 10 turns the lowest hardness was measured. This is a result of incomplete welding of the powder and therefore crack-like defects. The specimens with 30 and 63 rotations show a similar hardness, which indicates that an equilibrium state is reached.

The SEM micrographs indicate that HPT is a process capable to consolidate metallic glass powder by welding the particles together. In the past HPT has been already used to produce nanocomposites by co-deforming of two different materials. Hence, the next step is producing metallic glass composites. The second component next to a metallic glass can be a crystalline metal, but also another metallic glass. Mixing crystalline and amorphous metals together changes the deformation behavior and so, the formation of one fatal shear band can be prevented and the mechanical properties could be 
improved [21,31,32]. Metallic glass/metallic glass composites will also show different properties, because the two metallic glasses differ in the chemical composition and the near range ordering will vary. The interfaces between the two metallic glasses will strongly influence the properties of the composite.

\section{Conclusions}

(i) Bulk metallic glass specimens can be produced by consolidation and deforming metallic glass powder with HPT; (ii) fully dense samples without cracks and pores can be achieved as long as sufficient strain $(\gamma=600)$ is applied to weld the powder particles; the necessary strain is significantly larger than in the case of consolidation of metal powder, due to the more localized deformation in metallic glasses; (iii) during HPT at room temperature no crystallization of the Zr-based metallic glass was observed, the specimens were found to be fully amorphous; (iv) a hardness of up to $500 \mathrm{HV}$ is measured.

With this processing route it is possible to create new materials such as metal/metallic glass composites and metallic glass/metallic glass composites (two different metallic glasses). Those materials are expected to show interesting properties as the new interfaces will change dramatically the properties of metallic glasses.

\section{Acknowledgments}

Funding for this work has been provided by the European Research Council under ERC Grant Agreement No. 340185 USMS and by the Austrian Science Fund (FWF) under Project: T512-20.

\section{Author Contributions}

Lisa Krämer processed the samples, did the SEM and XRD investigations, carried out the hardness measurements and created the initial draft. Karoline Kormout carried out high resolution TEM imaging and recorded diffraction patterns. Daria Setman characterized the material with DSC measurements. Yannick Champion provided the metallic powder. Reinhard Pippan formulated the idea of this work. All authors discussed the results, contributed ideas, participated in the manuscript preparation and approved the final manuscript.

\section{Conflicts of Interest}

The authors declare no conflict of interest.

\section{References}

1. Greer, A.L. Metallic glasses ... on the threshold. Mater. Today 2009, 12, 14-22.

2. Löffler, J. Bulk metallic glasses. Intermetallics 2003, 11, 529-540.

3. Ashby, M.F.; Greer, A.L. Metallic glasses as structural materials. Scr. Mater. 2006, 54, 321-326.

4. Wang, W.H.; Dong, C.; Shek, C.H. Bulk metallic glasses. Mater. Sci. Eng. R 2004, 44, 45-89.

5. Packard, C.E.; Schuh, C.A. Initiation of shear bands near a stress concentration in metallic glass. Acta Mater. 2007, 55, 5348-5358. 
6. Liu, X.J.; Xu, Y.; Hui, X.; Lu, Z.P.; Li, F.; Chen, G.L.; Lu, J.; Liu, C.T. Metallic liquids and glasses: Atomic order and global packing. Phys. Rev. Lett. 2010, 105, 155501.

7. Schroers, J.; Kumar, G.; Hodges, T.M.; Chan, S.; Kyriakides, T.R. Bulk metallic glasses for biomedical applications. JOM 2009, 61, 21-29.

8. Inoue, A.; Wang, X.M.; Zhang, W. Developments and applications of bulk metallic glasses. Rev. Adv. Mater. Sci. 2008, 18, 1-9.

9. Lu, Z.P.; Liu, C.T. A new glass-forming ability criterion for bulk metallic glasses. Acta Mater. 2002, 50, 3501-3512.

10. Li, Y.; Poon, S.; Shiflet, G.; Xu, J.; Kim, D.; Löffler, J. Formation of bulk metallic glasses and their composites. MRS Bull. 2007, 32, 624-628.

11. Azushima, A.; Kopp, R.; Korhonen, A.; Yang, D.Y.; Micari, F.; Lahoti, G.D.; Groche, P.; Yanagimoto, J.; Tsuji, N.; Rosochowski, A.; et al. Severe plastic deformation (SPD) processes for metals. CIRP Ann.-Manuf. Technol. 2008, 57, 716-735.

12. Krämer, L.; Wurster, S.; Pippan, R. Deformation behavior of $\mathrm{Cu}$-composites processed by HPT. IOP Conf. Ser.: Mater. Sci. Eng. 2014, 63, 1-9.

13. Nowak, S.; Perriére, L.; Dembinski, L.; Tusseau-Nenez, S.; Champion, Y. Approach of the spark plasma sintering mechanism in $\mathrm{Zr}_{57} \mathrm{Cu}_{20} \mathrm{Al}_{10} \mathrm{Ni}_{8} \mathrm{Ti}_{5}$ metallic glass. J. Alloys Comp. 2011, 509, 1011-1019.

14. Xie, G.; Louzguine-Luzgin, D.; Kimura, H.; Inoue, A. Ceramic Particulate Reinforced $\mathrm{Zr}_{55} \mathrm{Cu}_{30} \mathrm{Al}_{10} \mathrm{Ni}_{5}$ Metallic Glassy Matrix Composite Fabricated by Spark Plasma Sintering. Mater. Trans. 2007, 48, 1600-1604.

15. Xie, G.; Louzguine-Luzgin, D.V.; Kimura, H.; Inoue, A. Nearly full density $\mathrm{Ni}_{52.5} \mathrm{Nb}_{10} \mathrm{Zr}_{15} \mathrm{Ti}_{15} \mathrm{Pt}_{7.5}$ bulk metallic glass obtained by spark plasma sintering of gas atomized powders. Appl. Phys. Lett. 2007, 90, 241902.

16. Valiev, R.Z.; Islamgaliev, R.K.; Alexandrov, I.V. Bulk nanostructured materials from severe plastic deformation. Progr. Mater. Sci. 2000, 2, 103-189.

17. Valiev, R.Z.; Estrin, Y.; Horita, Z.; Langdon, T.G.; Zechetbauer, M.J.; Zhu, Y.T. Producing bulk ultrafine-grained materials by severe plastic deformation. JOM 2006, 58, 33-39.

18. Estrin, Y.; Vinogradov, A. Extreme grain refinement by severe plastic deformation: A wealth of challenging science. Acta Mater. 2013, 61, 782-817.

19. Sabirov, I.; Pippan, R. Formation of a $\mathrm{W} 25 \% \mathrm{Cu}$ nanocomposite during high pressure torsion. Scr. Mater. 2005, 52, 1293-1298.

20. Bachmaier, A.; Pippan, R. Generation of metallic nanocomposites by severe plastic deformation. Int. Mater. Rev. 2013, 58, 41-62.

21. Sauvage, X.; Champion, Y.; Pippan, R.; Cuvilly, F.; Perriere, L.; Akhatova, A.; Renk, O. Structure and properties of a nanoscaled composition modulated metallic glass. J. Mater. Sci. 2014, $49,5640-5645$.

22. Sort, J.; Ile, D.C.; Zhilyaev, A.P.; Concustell, A.; Czeppe, T.; Stoica, M.; Surinach, S.; Eckert, J.; Baro, M.D. Cold-consolidation of ball-milled Fe-based amorphous ribbons by high pressure torsion. Scr. Mater. 2004, 50, 1221-1225. 
23. Van Steenberge, N.; Hobor, S.; Surinach, S.; Zhilyaev, A.; Houdellier, F.; Mompiou, F.; Baro, M.D.; Revesz, A.; Sort, J. Effects of severe plastic deformation on the structure and thermo-mechanical properties of $\mathrm{Zr}_{55} \mathrm{Cu}_{30} \mathrm{Al}_{10} \mathrm{Ni}_{5}$ bulk metallic glass. J. Alloys Comp. 2010, 500, 61-67.

24. Stolpe, M.; Kruzic, J.; Busch, R. Evolution of shear bands, free volume and hardness during cold rolling of a Zr-based bulk metallic glass. Acta Mater. 2014, 64, 231-240.

25. Shahabi, H.S.; Scudino, S.; Kühn, U.; Eckert, J. Metallic glass-steel composite with improved compressive plasticity. Mater. Des. 2014, 59, 241-245.

26. Concustell, A.; Baro, M.D.; Mear, F.O.; Surinach, S.; Greer, A.L. Structural relaxation and rejuvenation in a metallic glass induced by shot-peening. Philos. Mag. Lett. 2009, 89, 831-840.

27. Luo, K.; Li, W.; Zhang, H.Y.; Su, H.L. Changes of hardness and electronic work function of $\mathrm{Zr}_{41.2} \mathrm{Ti}_{13.8} \mathrm{Cu}_{12.5} \mathrm{Ni}_{10} \mathrm{Be}_{22.5}$ bulk metallic glass on annealing. Philos. Mag. Lett. 2011, 91, 237-245.

28. Champion, Y.; Perriére, L. Strain Gradient in Micro-Hardness Testing and Structural Relaxation in Metallic Glasses. Adv. Eng. Mater. 2014, doi:10.1002/adem.201400423.

29. Chen, X. Structure and hardness evolution of the scale of a Zr-based metallic glass during oxidation. J. Non-Cryst. Solids 2013, 362, 140-146.

30. Xu, Y.; Zhang, Y.; Li, J.; Hahn, H. Enhanced thermal stability and hardness of $\mathrm{Zr}_{46} \mathrm{Cu}_{39.2} \mathrm{Ag}_{7.8} \mathrm{Al}_{7}$ bulk metallic glass with Fe addition. Mater. Sci. Eng. A 2010, 527, 1444-1447.

31. Inoue, A.; Zhang, T.; Kim, Y.H. Synthesis of high strength bulk amorphous Zr-Al-Ni-Cu-Ag alloys with a nanoscale secondary phase. Mater. Trans. JIM 1997, 38, 749-755.

32. Hofmann, D.C. Bulk metallic glasses and their composites: A brief history of diverging fields. $J$. Mater. 2013, 2013, 1-8.

(C) 2015 by the authors; licensee MDPI, Basel, Switzerland. This article is an open access article distributed under the terms and conditions of the Creative Commons Attribution license (http://creativecommons.org/licenses/by/4.0/). 